\title{
Over-expressed human divalent metal transporter 1 is involved in iron accumulation in MES23.5 cells
}

\author{
Hua-Min $\mathrm{Xu}^{1}$, Hong Jiang ${ }^{1}$, Jun Wang, Bing Luo, Jun-Xia Xie * \\ Department of Physiology, Medical College of Qingdao University, No. 308 Ningxia Road, Qingdao, China \\ Received 30 May 2007; received in revised form 2 October 2007; accepted 19 October 2007 \\ Available online 21 December 2007
}

\begin{abstract}
Elevated iron accumulation has been reported in brain regions in some neurodegenerative disorders. However, the mechanism for this is largely unknown. Divalent metal transporter 1 (DMT1) is an important divalent cation transporter. The aim of the present study is to construct recombinant adenovirus encoding human DMT1 with iron responsive element (DMT1 + IRE) and infect MES23.5 dopaminergic cells in order to investigate the relationship between increased DMT1 + IRE expression and iron accumulation. The human DMT1 gene was obtained by RT-PCR from tissues of human duodenum. AdDMT1 + IRE was successfully constructed and identified by PCR, restriction endonuclease analyses and DNA sequencing, respectively. It was able to efficiently infect MES23.5 cells, which was confirmed by RT-PCR and Western blots. When incubated with $100 \mu \mathrm{M}$ ferrous iron for $6 \mathrm{~h}$, the intracellular iron levels dramatically increased in AdDMT1 + IRE infected MES23.5 cells compared to the solely adenovirus infected cells. Meanwhile, the levels of hydroxyl free radicals and malondialdehyde (MDA) in these cells increased. This led to the activation of caspase-3. The apoptosis in AdDMT1 + IRE infected cells was shown with hypercondensed nuclei using Hoechst staining. Analysis of DNA extracted from these cells showed the typical "ladder pattern", indicating the formation of mono- and oligonucleosomes. These results suggested that increased DMT1 + IRE expression in MES23.5 cells caused the increased intracellular iron accumulation. This resulted in the increased oxidative stress leading to ultimate cell apoptosis.
\end{abstract}

(C) 2007 Elsevier Ltd. All rights reserved.

Keywords: DMT1; Adenovirus; Ferrous iron; Oxidative stress; Apoptosis

\section{Introduction}

Iron is an essential element for many processes of life, including oxygen transport and electron transport during cellular respiration (Beard, 2003; Gordon, 2003). It is also a cofactor for nuclear, mitochondrial and cytosolic enzymes (Levenson and Tassabehji, 2004). However, excess iron can generate highly reactive hydroxyl radicals $\left({ }^{\bullet} \mathrm{OH}\right)$ by the Fenton reaction (Stohs and Bagchi, 1995), which can damage proteins, lipids and DNA. Recently many literatures have confirmed that iron plays a key role in Parkinson's disease (PD) and other neurodegenerative diseases (Gotz et al., 2004; Wang et al., 2004, 2007; Youdim et al., 2004; Berg and Hochstrasser, 2006; Jiang et al., 2006, 2007). Increased iron content was found in the substantia nigra pars compacta $(\mathrm{SNpc})$ of parkinsonian brains (Atasoy et al.,

\footnotetext{
* Corresponding author. Tel.: +86 532 85955891; fax: +86 53283780136 .

E-mail address: jxiaxie@126.com (J.-X. Xie).

${ }^{1}$ These authors are the co-first authors.
}

2004; Gerlach et al., 2006). However, the underlying mechanisms of iron accumulation remain unclear. Traditionally, the transferrin (Tf)-Tf receptor (TfR) pathway is considered as a major pathway of cellular iron uptake. Previous studies have demonstrated that $\mathrm{Tf}$ or its receptor did not increase in the parkinsonian brain, indicating Tf-TfR pathway might not be responsible for iron accumulation in PD (Faucheux et al., 1993; He et al., 1999; Zhang et al., 2000). The iron deposit in the SNpc of the parkinsonian brain might occur by a different iron transport mechanism. The identification of divalent metal transporter 1 (DMT1) is the most important breakthrough in the field of mammalian iron metabolism. DMT1, also known as Nramp2 (nature resistance associated macrophage protein 2) or DCT1 (divalent cation transporter 1), is a major duodenal ferrous iron transporter (Gunshin et al., 1997; Fleming et al., 1997; CanonneHergaux et al., 1999). DMT1 exists in at least four distinct isoforms, which differ in both the C-terminus (with IRE and without IRE) and the N-terminus (two different promoters) (Gunshin et al., 1997; Lee et al., 1998). The function of DMT1 + IRE was investigated in this study, which encodes a 
protein of 561 amino acids and contains an iron regulatory element (IRE) in the $3^{\prime}$-untranslated regions.

DMT1 is involved in the brain iron metabolism (Burdo et al., 2001; Huang et al., 2004) and highly expressed in the neurons of the substantial nigra (SN) in PD, which correlates with the iron abnormally deposited in the same area (Andrews et al., 1999). Our previous studies showed increased DMT1 expression and elevated iron levels in the SNpc of PD mouse model (Jiang et al., 2003). In the present study, we aim to verify the hypothesis that increased DMT1 expression caused the iron accumulation. We chose MES23.5 cells as the experimental neuronal model, a dopaminergic cell line hybridized from murine neuroblastoma-glioma N18TG2 cells with rat mesencephalic neurons exhibiting several properties similar to the primary neurons originated in the SN (Crawford et al., 1992). We employed a gene reconstruction technique to construct recombinant adenovirus expression vector encoding human DMT1 + IRE (AdDMT1 + IRE). Intracellular iron levels were measured in MES23.5 cells infected with AdDMT1 + IRE, and subsequent iron-induced apoptosis were conducted.

\section{Materials and methods}

\subsection{Materials}

Unless otherwise stated, all chemicals were purchased from Sigma Chemical Co. (St. Louis, MO, USA). The primary DMT1 + IRE antibody was purchased from the ADI (ADI, San Antonio, TX, USA). PmeI and PacI were from NEB (NEB, MA, USA). HindIII, KpnI and PMD18-T simple vector were from TaKaRa (TaKaRa Biotechnology Co., Ltd.). HEK293 cells, pAdtrackCMV, pAdeasy1, DH10B, JM109 were obtained from Dr. Yi-Ming Shao of Chinese Center for Disease Control and Prevention. Lipofectamine 2000 was from Promega. Dulbecco's modified Eagle's medium (DMEM) and Dulbecco's modified Eagle's medium Nutrient Mixture-F12 (DMEM/F12) were from Gibco (Gibco, Grand Island, NY, USA). The PE-conjugated monoclonal active caspase-3 antibody apoptosis kit was from BD Bioscience Company (BD Biosciences pharmingen, Franklin Lakes, NJ, USA). MDA and hydroxyl radicals reagent kits were from Nanjing Institute of Jiancheng Biological Engineering. Hoechst 33258 was from Beyotime (Jiangsu, China). Other chemicals and regents available were from local commercial sources.

\subsection{Total RNA extraction and nested reverse transcriptional (RT)- $P C R$}

Total RNA was isolated by using Trizol Reagent from frozen tissues of human duodenum according to the manufacturer's instructions. Then $2 \mu \mathrm{g}$ of total RNA was reverse-transcribed in a $20 \mu \mathrm{l}$ reaction using reverse-transcription system. In order to obtain a full-length gene, nested PCR was used. Primers were designed using computer software (Primer Premier 5.0) based on sequences with Gene Bank accession numbers AB004875. In the first round of amplification, the forward primer was 5'-AGGGTACCTCTAAGAACTCAGCCACTCAG-3'. The reverse primer was $5^{\prime}$-ACGAAGCTTAGCTTTTCAAAGATCCCACC- $3^{\prime}$. The diluted (1:100) resulting product was used as template for secondary PCR reactions. The secondary forward primer was changed to $5^{\prime}$-AAGGTACCACCATGGTGCTGGGTCCTG- ${ }^{\prime}$, which included a KpnI site. The reverse primer for DMT1 + IRE was 5'-GCAAGCTTTTCACACAGTAAACCATAGAAACAC- $3^{\prime}$, which introduced a HindIII restriction site. High-fidelity PCR reactions were ensured by using a mixture of Taq DNA polymerase and high-fidelity DNA polymerase pyrobest in a ratio of 9:1. Thermocycling was carried out as follows: $94{ }^{\circ} \mathrm{C}$ for $5 \mathrm{~min}$, then 30 cycles of $94{ }^{\circ} \mathrm{C}$ for $1 \mathrm{~min}, 62{ }^{\circ} \mathrm{C}$ for 1 min and $72{ }^{\circ} \mathrm{C}$ for $2 \mathrm{~min}$, followed by $72^{\circ} \mathrm{C}$ for $10 \mathrm{~min}$. The PCR products were cloned into a PMD18-T simple vector for sequencing.

\subsection{Construction of recombinant adenovirus and virus package}

Human DMT1 + IRE gene was digested from PMD18-T simple vector with KpnI and HindIII, then cloned into the shuttle plasmid pAdTrack-CMV containing a green fluorescent protein (GFP) reporter gene. Linearized pAdCMV-DMT1 + IRE was subsequently co-transformed into $E$. coli strain BJ5183 cells along with a supercoiled adenoviral backbone plasmid pAdeasy1. Recombinants were confirmed by PCR and endonuclease analyses. PacI digested recombinant was then transfected with lipofectamine 2000 into 293 cells to package viruses (He et al., 1998). The recombinant adenovirus was named AdDMT1 + IRE. An empty adenovirus without the gene of interest was also constructed as a control named AdGFP.

\subsection{Cell culture and MES23.5 cells infection}

HEK293 cells (E1-transformed human embryonic kidney cells) were maintained in a growth medium DMEM supplemented with $10 \%$ fetal bovine serum (FBS), 100 units $/ \mathrm{ml}$ of penicillin and $100 \mathrm{mg} / \mathrm{ml}$ of streptomycin at $37^{\circ} \mathrm{C}$ in a humid $5 \% \mathrm{CO}_{2}, 95 \%$ air environment. Dopaminergic cell line MES23.5 cells were offered by Dr. Wei-Dong Le (Baylor College of Medicine, TX, USA). They were cultured in DMEM/F12 containing Sato's components growth medium supplemented with 5\% FBS, 100 units/ml of penicillin and $100 \mathrm{mg} /$ $\mathrm{ml}$ of streptomycin at $37{ }^{\circ} \mathrm{C}$, in a humid $5 \% \mathrm{CO}_{2}, 95 \%$ air environment. For experiments, cells were seeded at a density of $1 \times 10^{5} / \mathrm{cm}^{2}$ in the plastic flasks or on glass coverslips.

MES23.5 cells were resuspended in DMEM/F12 with 5\% FBS supplement and seeded at a density of $1 \times 10^{5} / \mathrm{ml} 24 \mathrm{~h}$ prior to infection. When the confluence is about $50-70 \%$, cells were infected with AdGFP and AdDMT1 + IRE, respectively. GFP fluorescence was monitored at indicated time to verify the infective efficiency. Thirty-six hours after infection, cells were used for the further experiments.

\subsection{Semi-quantitative reverse transcriptional (RT)-PCR}

RNA was isolated from infected MES23.5 cells using Trizol Reagent. We amplified $380 \mathrm{bp}$ with the primer (sense: $5^{\prime}$-TAGGTACCATGCAGTATCCCAAGGTCCCAC- $3^{\prime}$, antisense: $5^{\prime}$-AGCAAGCTTTTAGCCCACAGCCTGTTCAATC- $3^{\prime}$ ). The samples were heated at $95^{\circ} \mathrm{C}$ for $5 \mathrm{~min}$ and the subsequent cycles were performed at three temperature steps: $94{ }^{\circ} \mathrm{C}$ for $30 \mathrm{~s}, 54^{\circ} \mathrm{C}$ for $30 \mathrm{~s}$, $72{ }^{\circ} \mathrm{C}$ for $45 \mathrm{~s}$, and after 32 cycles an additional $10 \mathrm{~min}$ for extension was carried out. Ethidium bromide stained gels were scanned and qualified using Tanon Image Software; DMT1 levels were normalized with respect to GAPDH levels.

\subsection{Western blots}

Cells were lysed directly on the culture dishes using lysis buffer $(50 \mathrm{mmol} / 1$ Tris- $\mathrm{HCl}, 150 \mathrm{mmol} / \mathrm{l} \mathrm{NaCl}, 1 \%$ Nonidet- $40,0.5 \%$ sodium deoxycholate, $1 \mathrm{mmol} / 1$ EDTA) plus $1 \mathrm{mM}$ PMSF and protease inhibitors (pepstatin $1 \mu \mathrm{g} / \mathrm{ml}$, aprotinin $1 \mu \mathrm{g} / \mathrm{ml}$, leupeptin $1 \mu \mathrm{g} / \mathrm{ml}$ ). The protein concentration was determined by the Bradford assay kit (Bio-Rad Laboratories, Hercules, CA). Sixty micrograms total proteins were separated using $10 \%$ SDS-polyacrylamide gels and then transferred to PVDF membranes. After overnight blocking with $5 \%$ non-fat milk at $4{ }^{\circ} \mathrm{C}$, the membranes were incubated with rabbit anti-rat DMT1 + IRE antibody (1:2000, ADI, USA) for $1 \mathrm{~h}$ at room temperature. Anti-rabbit secondary antibodies conjugated to horseradish peroxidase were used at a dilution of 1:500. Cross-reactivity was visualized using ECL Western blotting detection reagents and then was analyzed through scanning densitometry by Tanon Image System. $\beta$-Actin was detected by mouse anti- $\beta$-actin monoclonal antibody $(1: 10,000$, Sigma, USA) according to similar procedures to ensure equal sample protein loading.

\subsection{MTT assay}

Cells were treated with different doses of ferrous iron, freshly prepared with stock solutions. After incubation in MTT $(5 \mathrm{mg} / \mathrm{ml})$ for $4 \mathrm{~h}$ at $37^{\circ} \mathrm{C}$, cell injury was measured by colorimetric assay (TECAN, Austria). 
2.8. Intracellular iron concentration assay and hydroxyl free radicals and lipid peroxidation measurements

Cells were treated with $100 \mu \mathrm{M}$ ferrous iron $\left(\mathrm{FeSO}_{4}\right)$ for additional $6 \mathrm{~h}$. After washed with cold PBS, cells lysed with nitric acid. Intracellular iron concentration was measured using inductively coupled plasma (ICP-2) detector. For the intracellular hydroxyl free radicals and lipid peroxidation measurements, cells were lysed by ultrasound and protein concentration was measured by the Bradford method. Intracellular hydroxyl free radicals measurement was performed as described before (Han et al., 2004), using a commercially available kit following the manufacture's recommended procedures (Nanjing Institute of Jiancheng Biological Engineering, China). The levels of MDA (malondialdehyde), a terminal product of lipid peroxidation, were measured as the indication of lipid peroxidation, using a commercially available kit (Nanjing Institute of Jiancheng Biological Engineering, China). The thiobarbituric acidreactive substrates were quantified using 1, 1, 3, 3-tetraethoxypropane as the standard. The absorbance at $532 \mathrm{~nm}$ was measured with a colorimetry. Data were presented as the mean \pm S.E.M. of each group. Each experiment was repeated three times.

\subsection{Active caspase-3 assay}

Active caspase- 3 assay was measured according to the manufacturer's protocol (BD Pharmingen ${ }^{\mathrm{TM}}$, BD Biosciences pharmingen, USA). Briefly, cell treatment was the same as the above. After washing twice with cold PBS, cells were resuspended in Citofix/Cytoperm ${ }^{\mathrm{TM}}$ solution at a concentration of $1 \times$ $10^{6}$ cells $/ 0.5 \mathrm{ml}$. After incubation for $20 \mathrm{~min}$, cells were washed with Perm/ Washing buffer twice, and then incubated in Perm/Wash buffer with antibody (1:5). After washing once with Perm/Wash buffer, cells were resuspended with $0.5 \mathrm{ml} \mathrm{Perm} /$ Wash buffer and analyzed by flow cytometry. The percentage of positive cells reacting with the antibody was examined with Cellguest Software.

\subsection{Hoechst 33258 staining and DNA fragmentation detection}

Nuclear morphology was detected using the method described before (Yao et al., 2006). Cells were fixed, washed twice with PBS and stained with Hoechs 33258 staining solution according to the manufacturer's instructions (Beyotime, Jiangsu, China). Apoptotic cells were defined on the basis of nuclear morphology changes, such as chromatin condensation and fragmentation. The total number of condensed cells was counted manually by researchers blinded to the treatment schedule using unbiased stereology (West et al., 1991; Feng and Zhang, 2004) and a fluorescence Olympus microscope (Olympus, Japan). For each well, we delineated a $400 \mu^{2}$ frame and counted all condensed and normal nuclei with at least 10 different fields in one well. Average sum of condensed and normal nuclei was calculated per well. The data were expressed as a percentage of condensed nuclear number to the total number.

The "ladder pattern" of DNA fragmentation was detected by agarose gel electrophoresis after iron treatment. DNA from cultured MES23.5 cells was isolated following the instructions of the DNA ladder detection kit (BioDevTech., China). After staining with ethidium bromide $(0.5 \mu \mathrm{g} / \mathrm{ml})$, DNA bands were visualized by UV transillumination.

\subsection{Statistical analysis}

Each experiment was performed at least three times, and the results are presented as mean \pm S.E.M. One-way analysis of variance (ANOVA) or $t$-test was used to compare the differences between means. A level of $P<0.05$ was considered to be statistically significant.

\section{Results}

\subsection{AdDMT1 + IRE efficiently infected MES23.5 cells}

Human DMT1 + IRE gene was amplified by RT-PCR. The length of DMT1 + IRE was 1772 bp (Fig. 1A). The product was confirmed to be the correct sequence of human DMT1 cDNA. The constructed AdDMT1 + IRE was confirmed by PCR (Fig. 1B) and endonuclease analyses (Fig. 1C). Recombinant could yield a small fragment of $3.0 \mathrm{~kb}$, yet pAdeasy 1 could not yield the small fragment by PacI digesting, indicating the successful construction of recombinant adenovirus expression vector. AdDMT1 + IRE and AdGFP without human DMT1 + IRE gene were obtained after packaging and amplification in HEK293 cells. Recombinant adenoviruses AdDMT1 + IRE and AdGFP both contained green fluorescent protein (GFP) reporter gene, allowing us to measure infection frequency of infected MES23.5 cells (Fig. 2). Thirty-six hours after infection of MES23.5 cells, the infection efficiency reached to $60.2 \%$ in AdDMT1 + IRE infected cells and 57.8\% in AdGFP infected cells. Increased DMT1 expression was confirmed by RT-PCR and Western blots. Data showed that DMT1 + IRE mRNA (Fig. 3A) and protein levels (Fig. 3B) increased significantly in AdDMT1 + IRE infected cells compared to AdGFP infected cells.

\subsection{Cell viability reduced when treated with ferrous iron in AdDMT1 + IRE infected MES23.5 cells}

Different doses of ferrous iron were added to the culture medium. When incubation with $100 \mu \mathrm{M}$ ferrous iron for $24 \mathrm{~h}$,
(A)

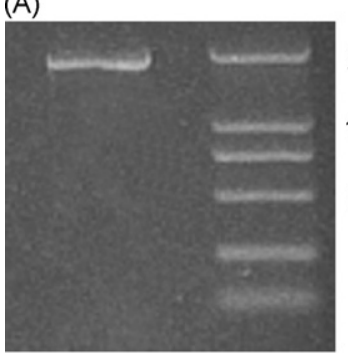

(B)

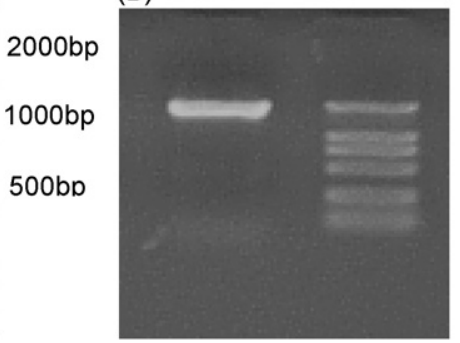

(C) 1

$2000 \mathrm{bp}$

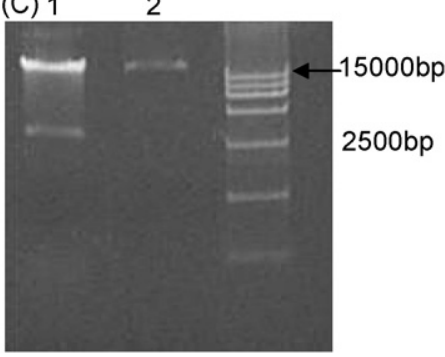

1. PAdDMT1+IRE
2. pAdeasy1

Fig. 1. Construction of recombinant adenovirus expression vector containing human DMT1 + IRE. (A) RT-PCR for the human DMT1 + IRE gene. The product of DMT1 + IRE is 1772 bp. (B) DMT1 + IRE expression in recombinant adenovirus plasmid AdDMT1 + IRE by PCR. (C) Recombinant adenovirus plasmid was digested by PacI. Recombinant could yield a smaller fragment of $3.0 \mathrm{~kb}$. Lane1: pAdDMT1 + IRE yielded a smaller fragment of $3.0 \mathrm{~kb}$. Lane2: pAdeasy1 could not yield the small fragment of $3.0 \mathrm{~kb}$. 
(A)

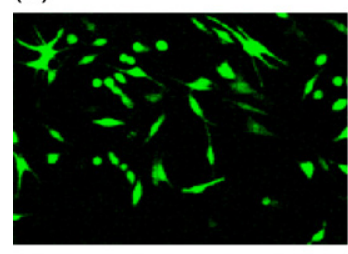

(a)

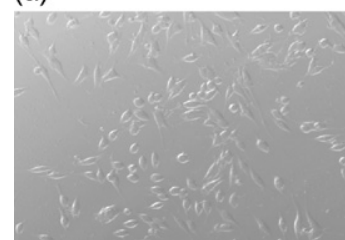

(B)

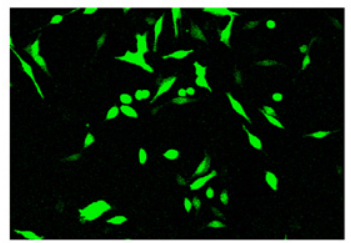

(b)

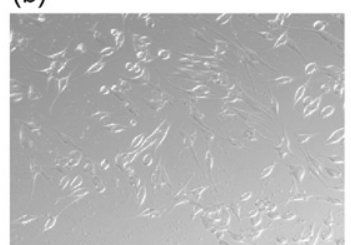

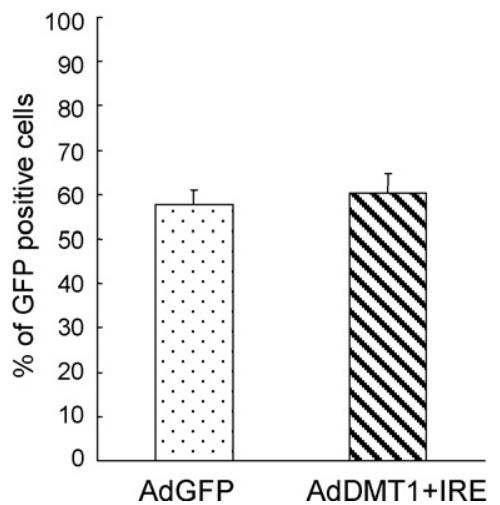

Fig. 2. GFP fluorescence expression was monitored after infection by confocal microscope. (A) GFP fluorescence expression in MES23.5 cells after infection with AdGFP for $36 \mathrm{~h}$ : (a) the same field of AdGFP infected MES23.5 cells by phase contrast microscopy. (B) GFP expression fluorescence in MES23.5 cells after infection with AdDMT1 + IRE for 36 h: (b) the same field of AdDMT1 + IRE infected cells by phase contrast microscopy. Magnification 200×. (C) The statistical analysis of infection efficiency. Data were presented as mean \pm S.E.M.

(A) $380 \mathrm{bp}$ $290 \mathrm{bp}$

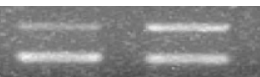
DMT1+IRE GAPDH

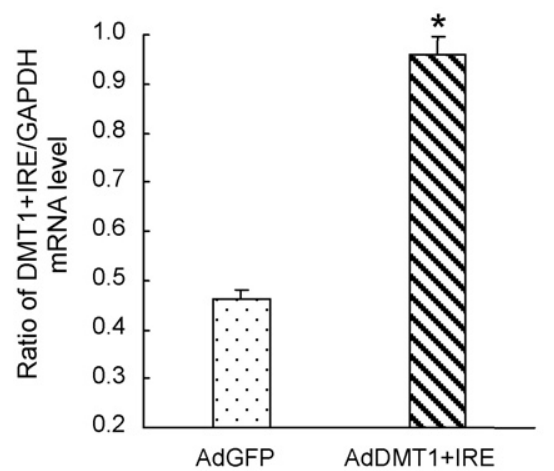

(B)
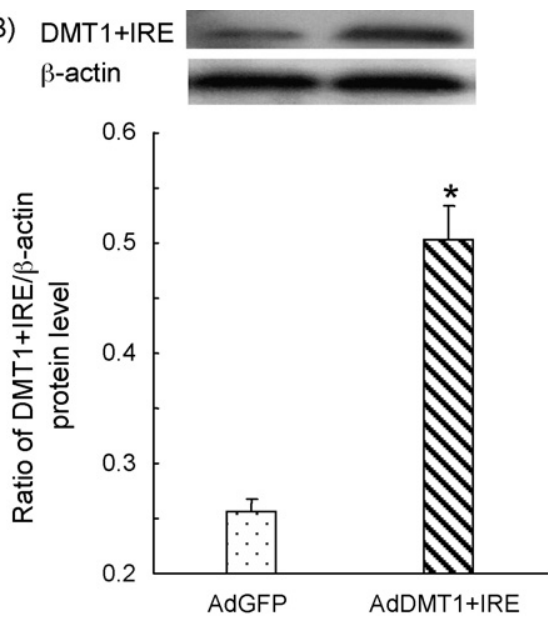

Fig. 3. DMT1 + IRE expression in MES23.5 cells. MES23.5 cells were infected with AdDMT1 + IRE for $36 \mathrm{~h}$, DMT1 + IRE mRNA and protein levels were detected. (A) DMT1 + IRE mRNA levels increased significantly after AdDMT1 + IRE infection compared with that of control. (B) The protein levels of DMT1 + IRE were higher in AdDMT1 + IRE infected cells than that of control. Data were presented as mean \pm S.E.M. $(* P<0.01$, compared with AdGFP infected cells).

there was a significant reduction in cell viability in AdDMT1 + IRE infected cells (Table 1). However, no significant change was observed in AdGFP infected cells. Low doses of ferrous iron had no effects on the cell viability in AdDMT1 + IRE infected cells. To avoid the influence of reduced cell number on the following experiments, we selected

\section{Table 1}

Changes of cell viability with different doses of ferrous iron treatment

\begin{tabular}{lc}
\hline Groups & MTT (\% of control) \\
\hline Control & $100.00 \pm 3.58$ \\
AdGFP $(50 \mu \mathrm{mol} / 1$ iron $)$ & $88.98 \pm 5.84$ \\
AdGFP $(100 \mu \mathrm{mol} / \mathrm{l}$ iron $)$ & $87.49 \pm 5.68$ \\
AdDMT1 + IRE $(100 \mu \mathrm{mol} / \mathrm{l}$ iron $)$ & $73.83 \pm 5.62^{*}$ \\
\hline
\end{tabular}

$F=5.55$. Data were presented as mean \pm S.E.M.

* $P<0.05$, compared with control.
$100 \mu \mathrm{M}$ ferrous iron incubated for $6 \mathrm{~h}$ for the further experiments.

\subsection{Intracellular iron levels, hydroxyl free radicals and lipid peroxidation increased in AdDMT1 + IRE infected MES23.5 cells after iron incubation}

To verify whether the increased expression of DMT1 in AdDMT1 + IRE infected MES23.5 cells was able to transport iron into the cells; the intracellular iron levels were detected by ICP-2. The results showed that the intracellular iron levels in AdDMT1 + IRE infected cells significantly increased compared to AdGFP infected cells and uninfected cells after iron treatment (Table 2). Our next question is whether the increased intracellular iron could cause the reactive oxidative stress. As expected, exposure to ferrous iron for $6 \mathrm{~h}$ intracellular hydroxyl 

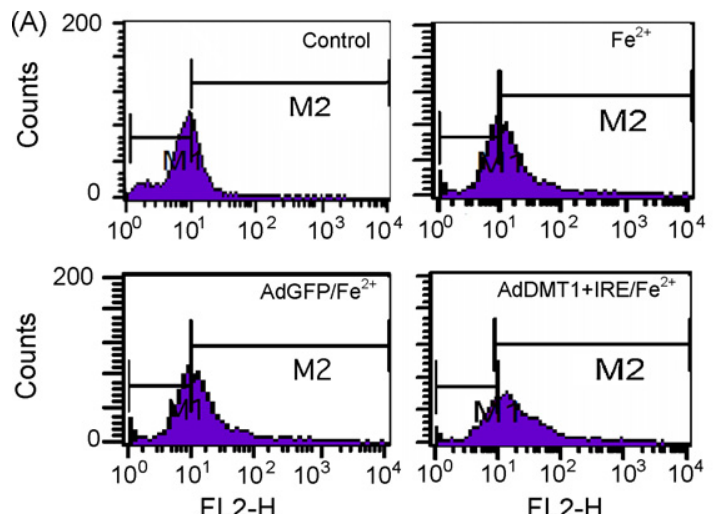

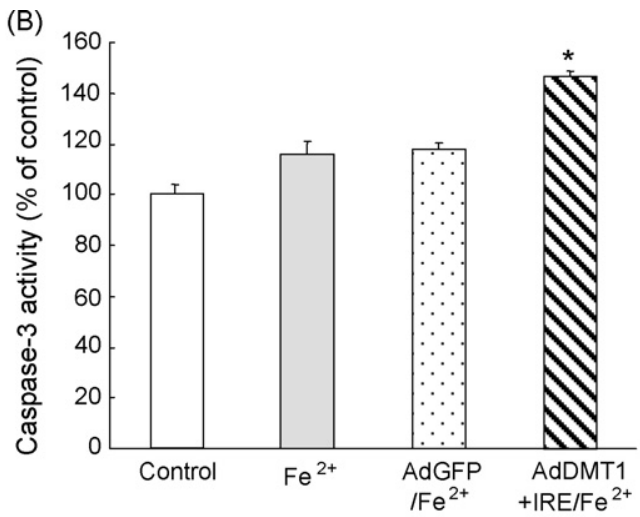

Fig. 4. Caspase-3 activity was increased in AdDMT1 + IRE infected MES23.5 cells after iron incubation. Infected MES23.5 cells were treated with 100 $\mu$ mol/1 ferrous iron for $6 \mathrm{~h}$ and activated caspase-3 levels were detected by flow cytometry. (A) Representatives of the fluometric assay. (B) Statistical analysis. Activated caspase-3 levels in AdDMT1 + IRE infected cells were higher than that in AdGFP infected cells. There was no significant difference between uninfected cells and AdGFP infected cells after iron treatment. Data were presented as mean \pm S.E.M. $(* P<0.01$, compared with AdGFP infected cells $)$.

Table 2

Cellular iron levels in MES23.5 cells and infected cells after ferrous iron incubation for $6 \mathrm{~h}$

\begin{tabular}{ll}
\hline Groups & Iron contents $\left(\mu \mathrm{g} / 10^{6}\right.$ cells $)$ \\
\hline Control & $0.41 \pm 0.09$ \\
$\mathrm{Fe}^{2+}$ & $0.64 \pm 0.03$ \\
AdGFP/Fe & $2+$ \\
AdDMT $1+\mathrm{IRE} / \mathrm{Fe}^{2+}$ & $0.62 \pm 0.01$ \\
\end{tabular}

$F=108.01$. Data were presented as mean \pm S.E.M.

* $P<0.01$, compared with AdGFP infected cells.

free radicals and MDA levels of cells infected with AdDMT1 + IRE showed a significant increase $(P<0.01)$ (Table 3).

\subsection{Caspase-3 activation was observed in AdDMT1 + IRE infected MES23.5 cells after iron incubation}

Caspase- 3 is a key protein in the process of apoptosis. Consistent with the above increased cellular ROS formation, activation of the effector caspase- 3 was also observed. The active caspase- 3 was measured using the PE-conjugated monoclonal active caspase-3 antibody apoptosis kit. As shown in Fig. 4, activated-caspase-3 positive cells in AdDMT1 + IRE infected cells markedly increased after exposure to ferrous iron compared to AdGFP infected cells. These results indicated that increased cellular iron levels caused by DMT1 could active the executive caspase-3 through free radicals in MES23.5 cells.

Table 3

Intracellular hydroxyl free radicals and MDA levels in MES23.5 cells and infected cells after ferrous iron incubation for $6 \mathrm{~h}$

\begin{tabular}{|c|c|c|}
\hline Groups & $\begin{array}{l}{ }^{\circ} \mathrm{OH} \text { concentration } \\
\text { (U/mg protein) }\end{array}$ & $\begin{array}{l}\text { MDA concentration } \\
\text { (nmol/mg protein) }\end{array}$ \\
\hline Control & $21.76 \pm 1.30$ & $1.59 \pm 0.04$ \\
\hline $\mathrm{Fe}^{2+}$ & $24.23 \pm 0.21$ & $1.89 \pm 0.18$ \\
\hline $\mathrm{AdGFP} / \mathrm{Fe}^{2+}$ & $25.34 \pm 0.22$ & $1.97 \pm 0.14$ \\
\hline AdDMT1 + IRE/Fe ${ }^{2+}$ & $33.09 \pm 0.92^{*}$ & $3.24 \pm 0.09^{*}$ \\
\hline
\end{tabular}

○H: $F=36.32$; MDA: $F=33.82$. Data were presented as mean \pm S.E.M.

${ }^{*} P<0.01$, compared wtih AdGFP infected cells.

\subsection{Cell apoptosis was found in AdDMT1 + IRE infected MES23.5 cells after iron incubation}

To further confirm the cell apoptosis, the nuclear morphology was analyzed by blue Hoechst 33258. In uninfected and AdGFP infected cells after iron treatment, nuclei appeared with regular contours and were round and large in size. However, the nuclei of AdDMT1 + IRE infected cells appeared hypercondensed (brightly stained) and fragmentation of chromatin (Fig. 5). We further detected DNA laddering in these cells. DNA extracted from AdDMT1 + IRE infected cells showed an apparent ladder pattern (Fig. 5F) after exposure to $100 \mu \mathrm{M}$ $\mathrm{FeSO}_{4}$ for $6 \mathrm{~h}$, which indicated the formation of mono- and oligonucleosomes. No apparent laddering occurred in uninfected cells and AdGFP infected cells.

\section{Discussion}

A growing body of evidence suggests that iron accumulation plays a key role in the etiology and pathology of neurodegenerative diseases, such as Parkinson's disease (Gotz et al., 2004; Berg and Hochstrasser, 2006). However, the underlying mechanisms of iron accumulation have not been fully elucidated. The identification of DMT1 provides an approach to investigate cellular mechanism of iron accumulation. In the present study, we successfully constructed the recombinant adenovirus encoding human DMT1 + IRE with Adeasy system. Because the infection does not interfere with the host genome, Adeasy system shows a low risk to induce alteration of the host DNA. Therefore, it has been wildly used to deliver gene expression (Chinsangaram et al., 2003; Wesley et al., 2004; Mascola et al., 2005). After its infection of MES23.5 cells, a significant increase in intracellular iron levels was observed, which is in agreement with other studies conducted in the COS7 cells and CHO cells (Worthington et al., 2000; Zhang et al., 2000).

Experimental evidence has supported a link between DMT1 and iron accumulation because of its iron uptake function. Increased DMT1 expression coincidentally correlated with the abnormal iron deposited in the same area as the neurons of the 
(A)

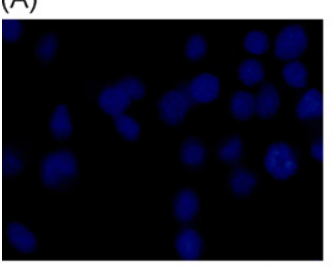

(B)
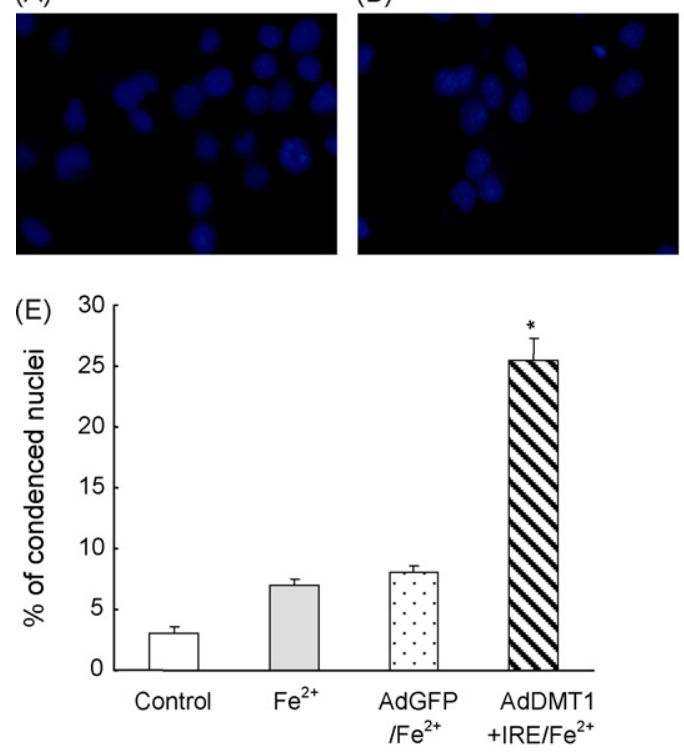

(C)

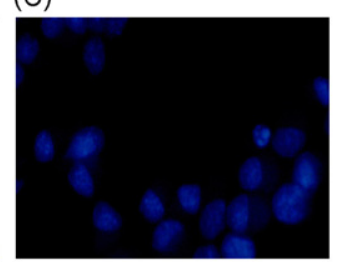

(D)

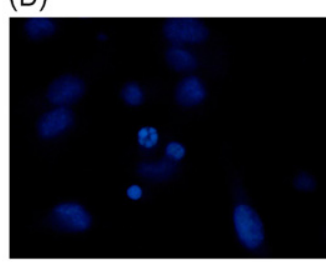

(F) $\quad$ a $\quad$ b $\quad c \quad d$

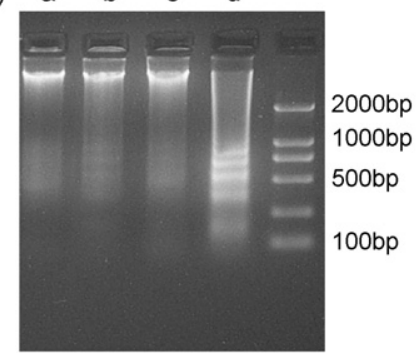

Fig. 5. Morphological changes and DNA laddering were observed in AdDMT1 + IRE infected MES23.5 cells after iron treatment for 6 h. A is the control; B-D were representative photographs of Hoechst staining of normal, AdGFP and AdDMT1 + IRE infected cells incubated with ferrous iron for 6 h. The nuclei of AdDMT1 + IRE infected cells appeared hypercondensed (brightly stained) and fragmentation of chromatin. Magnification $400 \times$. (E) The statistical analysis of condensed nuclei in different groups. Data were expressed as mean \pm S.E.M. of three independent experiments. (F) Agarose gel electrophoretic pattern in different groups. DNA extracted from AdDMT1 + IRE infected cells showed an apparent ladder pattern after exposure to $100 \mu \mathrm{M} \mathrm{FeSO}_{4}$ for 6 h. (a) Control; (b) Fe ${ }^{2+}$; (c) $\mathrm{AdGFP} / \mathrm{Fe}^{2+} ;$ (d) AdDMT1 + IRE/Fe ${ }^{2+}$.

substantial nigra in PD (Andrews et al., 1999; Jiang et al., 2003). However, whether DMT1 is the cause of iron accumulation is not fully understood. Expression of DMT1 on neurons suggests that they might participate in the iron uptake process in neurons (Suh and Samuel, 2003; Moos and Morgan, 2004; Aracena et al., 2006; Cheah et al., 2006; Shindo et al., 2006). In the present study, we provide direct evidence that increased expression of DMT1 could induce iron uptake. This supports the correlation of the increased DMT1 and elevated iron levels in parkinsonian brain and suggests the important role of DMT1 in iron accumulation in PD.

Oxidative stress plays a key role in PD (Youdim and BenShachar, 1990; Kidd, 2000; Jenner, 2003; Andersen, 2004), which is able to promote lipid peroxidation, oxidation of protein, and DNA damage. Iron is a key molecular involved in the oxidative stress, which is capable to catalyze $\mathrm{H}_{2} \mathrm{O}_{2}$ and form the highly reactive hydroxyl radicals resulting in increased oxidative damage (Jellinger et al., 1990). As shown in our study, increased intracellular iron caused an increase in the levels of intracellular hydroxyl free radicals and the formation of MDA.

Under certain pathological conditions oxidative stress may lead to apoptosis (Zhang et al., 2003). Mounting evidence has strongly implicated the involvement of apoptosis in the death of neurons following exposure to toxic compounds in the neurodegeneration of dopaminergic neurons (Andersen, 2001; Nagatsu, 2002; Tatton et al., 2003; Ekshyyan and Aw, 2004). The caspase family of cysteine proteases plays a key role in apoptosis. These enzymes participate in a cascade that is triggered in response to proapoptotic signals and culminates in cleavage of a set of proteins, resulting in disassembly of the cells (Thornberry and Lazebnik, 1998; Enari et al., 1998). We confirmed the presence of apoptosis in our experimental condition by detecting caspase- 3 activation, nuclear morphological changes and DNA fragmentation. These findings indicate that increased DMT1 expression could in deed lead to apoptosis in a caspase-3-dependent pathway.

In summary, recombinant adenoviral expression vector encoding human DMT1 + IRE protein was firstly constructed. After infection with AdDMT1 + IRE, increased cellular iron was detected after iron treatment. Elevated cellular iron induced oxidative stress, increased caspase- 3 activity and ultimately apoptosis. This supports the function of increased DMT1 expression in iron accumulation and the notion that increased DMT1 results in oxidative stress and apoptosis, processes known to occur in PD.

\section{Acknowledgements}

We thank Dr. Wei-dong Le to give us the MES23.5 cell line. This work was supported by grants from the National Program of Basic Research sponsored by the Ministry of Science and Technology of China (2006CB500704, 2007CB516700) and the National Foundation of Natural Science of China (no. 30400139, 30570649).

\section{References}

Andersen, J.K., 2001. Does neuronal loss in Parkinson's disease involve programmed cell death? Bioessays 23, 640-646.

Andersen, J.K., 2004. Iron dysregulation and Parkinson's disease. J. Alzheimer Dis. 6, 47-52. 
Andrews, N.C., Fleming, M.D., Gunshin, H., 1999. Iron transport across biological membranes. Nutr. Rev. 57, 114-123.

Aracena, P., Aguirre, P., Muñoz, P., Núñez, M.T., 2006. Iron and glutathione at the crossroad of redox metabolism in neurons. Biol. Res. 39, 157-165.

Atasoy, H.T., Nuyan, O., Tunc, T., Yorubulut, M., Unal, A.E., Inan, L.E., 2004. T2-weighted MRI in Parkinson's disease; substantia nigra pars compacta hypointensity correlates with the clinical scores. Neurol. India 52, 332-337.

Beard, J., 2003. Iron deficiency alters brain development and functioning. J. Nutr. 133 (Suppl. 1), 1468-1472.

Berg, D., Hochstrasser, H., 2006. Iron metabolism in Parkinsonian syndromes. Mov. Disord. 9, 1299-1310.

Burdo, J.R., Menzies, S.L., Simpson, I.A., Garrick, L.M., Garrick, M.D., Dolan, K.G., Haile, D.J., Beard, J.L., Connor, J.R., 2001. Distribution of divalent metal transporter 1 and metal transport protein 1 in the normal and Belgrade rat. J. Neurosci. Res. 66, 1198-1207.

Canonne-Hergaux, F., Gruenheid, S., Ponka, P., Gros, P., 1999. Cellular and subcellular localization of the Nramp2 iron transporter in the intestinal brush border and regulation by dietary iron. Blood 93, 4406-4417.

Cheah, J.H., Kim, S.F., Hester, L.D., Clancy, K.W., Patterson 3rd, S.E., Papadopoulos, V., Snyder, S.H., 2006. NMDA receptor-nitric oxide transmission mediates neuronal iron homeostasis via the GTPase Dexras1. Neuron 51, 431-440.

Chinsangaram, J., Moraes, M.P., Koster, M., Grubman, M.J., 2003. Novel viral disease control strategy: adenovirus expressing alpha interferon rapidly protects swine from foot-and-mouth disease. J. Virol. 77, 16211625.

Crawford, G.D., Le, W.D., Smith, R.G., Xie, W., Stefani, E., Appel, S.H., 1992 A novel N18TG2 X mesencephalon cell hybrid expresses properties that suggest a dopaminergic cell line of substantia nigra origin. J. Neurosci. 12, 3392-3398.

Ekshyyan, O., Aw, T.Y., 2004. Apoptosis: a key in neurodegenerative disorders Curr. Neurovasc. Res. 1, 355-371.

Enari, M., Sakahira, H., Yokoyama, H., Okawa, K., Iwamatsu, A., Nagata, S. 1998. A caspase-activated DNase that degrades DNA during apoptosis, and its inhibitor ICAD. Nature 391, 43-50.

Faucheux, B.A., Hirsch, E.C., Villares, J., Selimi, F., Mouatt-Prigent, A., JavoyAgid, F., Hauw, J.J., Agid, Y., 1993. Distribution of 125I-ferrotransferrin binding sites in the mesencephalon of control subjects and patients with Parkinson's disease. J. Neurochem. 60, 2338-2341.

Feng, Z., Zhang, J.T., 2004. Protective effect of melatonin on $\beta$-amyloidinduced apoptosis in rat astroglioma c6 cells and its mechanism. Free Radic. Biol. Med. 37, 1790-1801.

Fleming, M.D., Trenor 3rd, C.C., Su, M.A., Foernzler, D., Beier, D.R., Dietrich, W.F., Andrews, N.C., 1997. Microcytic anaemia mice have a mutation in Nramp2, a candidate iron transporter gene. Nat. Genet. 16, 383-386.

Gerlach, M., Double, K.L., Youdim, M.B., Riederer, P., 2006. Potential sources of increased iron in the substantia nigra of parkinsonian patients. J. Neural Transm. Suppl. 70, 133-142.

Gordon, N., 2003. Iron deficiency and the intellect. Brain Dev. 25, 3-8.

Gotz, M.E., Double, K., Gerlach, M., Youdim, M.B., Riederer, P., 2004. The relevance of iron in the pathogenesis of Parkinson's disease. Ann. N. Y. Acad. Sci. 1012, 193-208.

Gunshin, H., Mackenzie, B., Berger, U.V., Gunshin, Y., Romero, M.F., Boron, W.F., Nussberger, S., Gollan, J.L., Hediger, M.A., 1997. Cloning and characterization of a mammalian proton-coupled metal-ion transporter. Nature (Lond.) 388, 482-488.

Han, Y.T., Han, Z.W., Yu, G.Y., Wang, Y.J., Cui, R.Y., Wang, C.B., 2004 Inhibitory effect of polypeptide from Chlamys farreri on ultravioletAinduced oxidative damage on human skin fibroblasts in vitro. Pharmacol. Res. 49, 265-274.

He, T.C., Zhou, S., da Costa, L.T., Yu, J., Kinzler, K.W., Vogelstein, B., 1998. A simplified system for generating recombinant adenoviruses. Proc. Natl. Acad. Sci. U.S.A. 95, 2509-2514.

He, Y., Lee, T., Leong, S.K., 1999. Time-course and localization of transferrin receptor expression in the substantia nigra of 6-hydroxydopamine-induced parkinsonian rats. Neuroscience 91, 579-585.

Huang, E., Ong, W.Y., Connor, J.R., 2004. Distribution of divalent metal transporter-1 in the monkey basal ganglia. Neuroscience 128, 487-496.
Jellinger, K., Paulus, W., Grundke-Iqbal, I., Riederer, P., Youdim, M.B., 1990 Brain iron and ferritin in Parkinson's and Alzheimer's diseases. J. Neural Transm. Park. Dis. Dement. Sec. 2, 327-340.

Jenner, P., 2003. Oxidative stress in Parkinson's disease. Ann. Neurol. 53, 2636.

Jiang, H., Qian, Z.M., Xie, J.X., 2003. The increased DMT1 expression and iron content in MPTP-treated C57BL/6 mice. Acta Physiol. Sin. 55, 571-576.

Jiang, H., Luan, Z., Wang, J., Xie, J.X., 2006. Neuroprotective effects of iron chelator desferal on dopaminergic neurons in the substantia nigra of rats with iron overload. Neurochem. Int. 49, 605-609.

Jiang, H., Song, N., Wang, J., Ren, L.Y., Xie, J.X., 2007. Peripheral iron dextran induced degeneration of dopaminergic neurons in rat substantia nigra. Neurochem. Int. 51, 32-36.

Kidd, P.M., 2000. Parkinson's disease as multifactorial oxidative neurodegeneration: implications for integrative management. Altern. Med. Rev. 5, 502529.

Lee, P.L., Gelbart, T., West, C., Halloran, C., Beutler, E., 1998. The human Nramp2 gene: characterization of the gene structure, alternative splicing, promoter region and polymorphisms. Blood Cells Mol. Dis. 24, 199-215.

Levenson, C.W., Tassabehji, N.M., 2004. Iron and ageing: an introduction to iron regulatory mechanisms. Age. Res. Rev. 3, 251-263.

Mascola, J.R., Sambor, A., Beaudry, K., Santra, S., Welcher, B., Louder, M.K., 2005. Neutralizing antibodies elicited by immunization of monkeys with DNA plasmids and recombinant adenoviral vectors expressing human immunodeficiency virus type 1 proteins. J. Virol. 79, 771-779.

Moos, T., Morgan, E.H., 2004. The metabolism of neuronal iron and its pathogenic role in neurological disease: review. Ann. N. Y. Acad. Sci. $1012,14-26$

Nagatsu, T., 2002. Parkinson's disease: changes in apoptosis-related factors suggesting possible gene therapy. J. Neural Transm. 109, 731-745.

Shindo, M., Torimoto, Y., Saito, H., Motomura, W., Ikuta, K., Sato, K., Fujimoto, Y., Kohgo, Y., 2006. Functional role of DMT1 in transferrinindependent iron uptake by human hepatocyte and hepatocellular carcinoma cell, HLF. Hepatol. Res. 35, 152-162.

Stohs, S.J., Bagchi, D., 1995. Oxidative mechanisms in the toxicity of metal ions. Free Radic. Biol. Med. 18, 321-336.

Suh, Y.J., Samuel, D., 2003. Glycosylphosphatidylinositol-anchored ceruloplasmin is required for iron efflux from cells in the central nervous system. $\mathrm{J}$. Biol. Chem. 278, 27144-27148.

Tatton, G.W., Chalmers-Redman, R., Brown, D., Tatton, N., 2003. Apoptosis in Parkinson's disease: signals for neuronal degradation. Ann. Neurol. 53 (Suppl. 3), 61-72.

Thornberry, N.A., Lazebnik, Y., 1998. Caspases: enemies within. Science 281, 1312-1316.

Wang, J., Jiang, H., Xie, J.X., 2004. Time dependent effects of 6-OHDA lesions on iron level and neuronal loss in rat nigrostriatal system. Neurochem. Res. 29, 2239-2243.

Wang, J., Jiang, H., Xie, J.X., 2007. Ferroportin1 and hephaestin are involved in the nigral iron accumulation of 6-OHDA-lesioned rats. Eur. J. Neurosci. 25, 2766-2772.

Wesley, R.D., Tang, M., Lager, K.M., 2004. Protection of weaned pigs by vaccination with human adenovirus 5 recombinant viruses expressing the hemagglutinin and the nucleoprotein of $\mathrm{H} 3 \mathrm{~N} 2$ swine influenza virus. Vaccine 22, 3427-3434.

West, M.J., Slomianka, L., Gundersen, H.J., 1991. Unbiased stereological estimation of the total number of neurons in the subdivision of the rat hippocampus using the optical fractionator. Anatom. Rec. 231, 482-497.

Worthington, M.T., Browne, L., Battle, E.H., Luo, R.Q., 2000. Functional properties of transfected human DMT1 iron transporter. Am. J. Physiol. Gastrointest. Liver Physiol. 279, 1265-1273.

Yao, G., Yang, L., Hu, Y., Liang, J., Hou, Y., 2006. Nonylphenol-induced thymocyte apoptosis involved caspase-3 activation and mitochondrial depolarization. Mol. Immunol. 43, 915-926.

Youdim, M.B., Ben-Shachar, D., 1990. The neurotoxic component in Parkinson's disease may involve iron-melanin interaction and lipid peroxidation of substantia nigra. In: Dostert, P., Riederer, P., Strolin-Benedetti, M., Roncucci, R. (Eds.), Early Markers in Parkinson's and Alzheimer's Diseases. Springer-Verlag, Vienna, pp. 111-122. 
Youdim, M.B., Stephenson, G., Ben Shachar, D., 2004. Ironing iron out in Parkinson's disease and other neurodegenerative diseases with iron chelators: a lesson from 6-hydroxydopamine and iron chelators, desferal and VK28. Ann. N. Y. Acad. Sci. 1012, 306-325.

Zhang, L., Lee, T., Wang, Y., Soong, T.W., 2000. Heterologous expression, functional characterization and localization of two isoforms of the monkey iron transporter Nramp2. Biochem. J. 349, 289-297 (Printed in Great Britain).

Zhang, Z.H., Wei, T.T., Hou, J.W., Li, G.S., Yu, S.Z., Xin, W.J., 2003. Iron-induced oxidative damage and apoptosis in cerebellar granule cells: attenuation by tetramethylpyrazine and ferulic acid. Eur. J. Pharmacol. 467, 41-47. 